International Journal of Health Sciences
Available online at http://sciencescholar.us/journal/index.php/ijhs
Vol. 3 No. 3, December 2019, pages: 44 54
e-ISSN: 2550-696X, p-ISSN: 2550-6978
https://doi.org/10.29332/ijhs.v3n3.369

\title{
Laterality and Pre-Reading Processes at an Early Age
}

\author{
CrossMark \\ Liza María Cedeño Cedeño a , Telly Yarita Macías Zambrano b, Julio César Zevallos Rengifo c, \\ Karla Mercedes Mendoza Loor ${ }^{\mathrm{d}}$
}

Article history: Received 27 May 2019, Accepted: 31 August 2019, Published: 27 November 2019

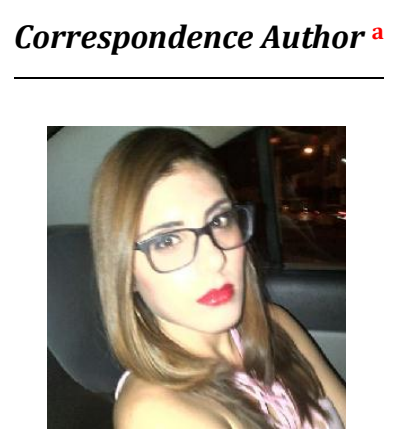

Keywords

development;

early ages;

early stimulation;

laterality;

pre-reading;

\begin{abstract}
Preschool ages are vital to the processes related to the acquisition and consolidation phases of defined laterality in children who will take advantage of this dimension to obtain favorable results in their academic performance and neuropsychological development. In this research, we intend to analyze the relationship between laterality at an early age and the construction of prereading processes through application programs and specific tests (such as the Martin Lobo adapted test); The sample of the same corresponds to 10 children attending the Children's Center of Good Living "Caritas Felices". In conclusion, it managed to demonstrate the impact of stimulation on interhemispheric interconnection and pre-reading processes. As part of the intervention program, both educators of the children's center and parents pledged to participate in a laterality training program in order to prevent and intervene in subsequent neuropsychological problems.
\end{abstract}

e-ISSN: 2550-696X, p-ISSN: 2550-6978 ${ }^{\circ}$ Copyright 2019. The Author. SS Journals Published by Universidad Técnica de Manabí. This is an open-access article under the CC BY-SA 4.0 license (https://creativecommons.org/licenses/by-sa/4.0/) All rights reserved.

\section{Contents}

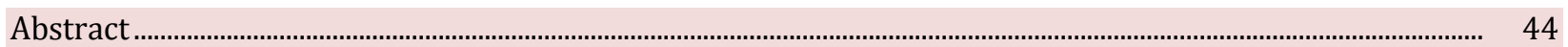

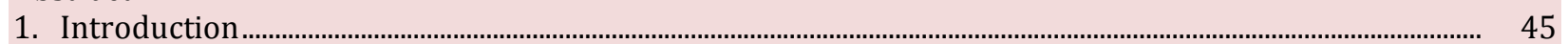

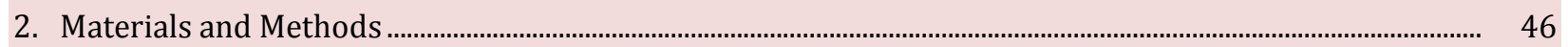

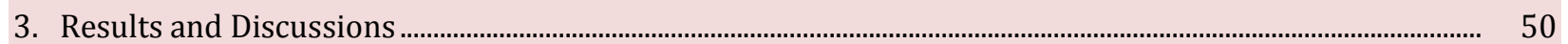

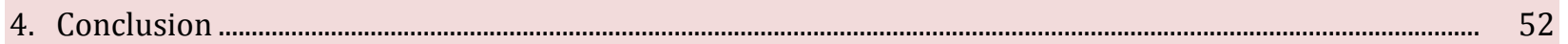

Acknowledgments.................................................................................................................................................... 52

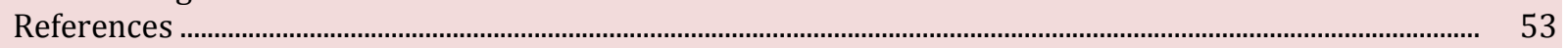

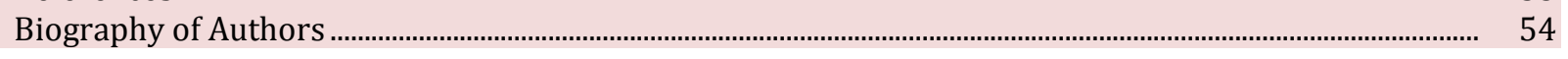

a Instituto Superior Tecnológico Paulo Emilio Macías, Portoviejo, Ecuador

b Instituto Superior Tecnológico Paulo Emilio Macías, Portoviejo, Ecuador

c Instituto Superior Tecnológico Paulo Emilio Macías, Portoviejo, Ecuador

d Instituto Superior Tecnológico Paulo Emilio Macías, Portoviejo, Ecuador 


\section{Introduction}

The human brain is composed of two hemispheres, these two structures have functional differences, one of these indicators is body laterality; same that refers to the preference for the use of the certain side of the body for different daily activities. Laterality is conceptualized as the predominance that has one side over the other, usually the left of the body on its side, in this case, the opposite, or vice versa (Portellano, 2012) cited by (González, 2016); according to the parts of the body, these can be eye, hand, foot, or ear (Mera, 2013). One of the main causes of learning disorders is due to the alteration of laterality. This function is also related to the Spatio-temporal orientation of sequential processes with a greater degree of complexity at the cognitive and motor level. Each side of the body is related to a certain body axis divided into the right and left side, therefore this preference can be given in the functionality of the hand, foot, eye, and ear (González, 2016). Hence the concept of the dominant hemisphere, although anatomically the body is symmetrical, there are cerebral asymmetries that present to a greater or lesser degree interference with the actions and thoughts of the individual.

Hemispheric dominance is a key factor with the language in which the first five years lived are consolidated; it is during this stage that the latency periods are presented, where the left and right sides take turns; It is at this stage that the child can affirm his definitive laterality until the age of seven. Many authors agree that this laterality usually adjusts, generally, in the age of pre-adolescence (González, 2016). Likewise, it is necessary to take into account that laterality is usually related and determined according to the dominance of one cerebral hemisphere over another, and hence the fact of having a preferred motor reflex type (Conde, 2004). According to all of the above, laterality can be considered as the equivalent of a reflex, which is evidenced externally by its motor dominance, but in its brain by hemispheric control; From the previous statement it is fair and necessary to take into account the importance of respecting and correct creolization of the laterality of the individual, so intervening in the process prematurely, would not only be a mistake but could manifest itself as motor delays with no remediable repercussions (Lenneberg, 1967; Sánchez \& Coveñas, 2013; Anthony et al., 2017).

The development of laterality is not innate, but it goes through different stages of development alongside the child, this is how the process of lateralization of the subject begins, understanding that its next step includes the pre-lateral phases, that until the moment in which I managed to act the corpus callosum, the body responsible and committed to the different connections of the hemispheres during vital stages such as the contralateral. Spionek (1985) cited by (González, 2016), referred to an investigation in which he relates leftright orientation, thanks to it It was allowed to establish new phases that clarify the issue of lateral dominance until the activation of the corpus callosum responsible for the connections is achieved interhemispheric in the contralateral stage, to later reach the establishment of laterality in the lateral stage, also (Spionek, 1985; Pérez et al., 2018), conducted a study related to the left-right orientation where he also established four phases of lateral establishment.

On the other hand, there is a point in the life of the infant in which different stages related to laterality begin to be fulfilled, these related to the consolidation of this predominance. This previous point is one of the main causes for which in many educational establishments problems of literacy or motor work are evidenced, this thanks to the contradictory laterality, originated from cognitive and motor difficulties corresponding to literacy. That consolidation of laterality is related to the best known with the passing of the years, these are left-handed and right-handed lateral dominance, both known and constituted in the large percentage of individuals. According to (Pérez, 1999) cited in (Portellano, 2012), no more than 10\% of the world's population is left-handed, being a coincident and wholesale factor, but at the same time of lesser eventuality. When the lateralization is completely homogeneous, regardless of which of the hemicibodies is manifested, the individual will present a lower number of problems for literacy; however, there are other types of laterality. The heterogeneous laterality, is in which it is more evident to distinguish the various difficulties of language this is stated by González (2016), who in his study on laterality cites (Mayolas et al., 2010) and (Portellano, 2010), referring that during the process of reading and writing, there are difficulties such as cross lateralization, ambidextrous, another is the opposite, one called undefined laterality.

To identify the types of laterality, the criteria to define them must be presented (Moneo, 2014), among them they are presented according to their dominant hand, according to their nature, according to their

Cedeño, L. M. C., Zambrano, T. Y. M., Rengifo, J. C. Z., \& Loor, K. M. M. (2019). Laterality and pre-reading processes at an early age. International Journal of Health Sciences, 3(3), 44-54.

https://doi.org/10.29332/ijhs.v3n3.369 
intensity, according to their predominant or preferred hemisphere: In the corresponding order it can be understood that the first one is related to the actions that the subject performs with the preferred hand, in This case, activities how to throw a ball or write. The second, by its nature, could take into account both neuropsychological and cell maturation processes; being these differentiated by the signs of progress that are reflected in the visual, tactile and auditory field. On the other hand, according to the intensity, which would be for the repetition of the use of a part of the body, being the person who is most comfortable with the left hand, left-handed people, those who express their preference for the right hand, right-handed and the Finally, he who has no problem with reflecting a preference, ambidextrous.

Finally, if one speaks of a predominant hemisphere, a brief classification can be mentioned, which includes both homogeneous dextrality and homogeneous left-handedness. In this area, it is in which it shows the cross laterality, in which a part of the body is used, contrary to those of the other parts of the body. When mentioning other types of relevant lateralities according to other studies carried out, it can be mentioned, the right-handed homogeneous laterality, which, as its name mentions, is defined by the preference to execute the right-sided activities of the body, both of its parts as of its hemispheric execution. The left-sided homogeneous laterality coincides, like the previous one, with the concept and defines the dominance of its segments and parts because it is preferably left (González, 2016). And, finally, one of the terms that is most coined and revealed in this work, the cross lateralized, in which the defined lateral preference is conceptualized as heterogeneity, which means that not all parts of the body can be constituted Due to right-handed or lefthanded dominance, there may be a shock or even a friction between the two, this being one of the main conflicts present in pre-writing works (González, 2016). An example is what he mentions Sassano (1989), cited by (González, 2016) there are motor centers which do not have an equitable level of development in both cerebral hemispheres; this explains the cases of subjects in which the person can be left-handed visual level, but at the same time it is right-handed at manual or foot level, among the studies reviewed, relevant information was collected on individuals with laterality difficulties, such as ambidextrous, severe learning problems, or attention and hyperactivity disorders usually occur (ADHD), or even problem how, under academic performance, dyslexia, confusion on the right side to the left and vice versa, or language problems. This demonstrates the clear impact of this difficulty of lateralization (González, 2016). of the present investigation, we can point to the importance that is evidenced in the different serious learning problems, such as trust Orno for attention deficit hyperactivity disorder (ADHD), language problems, poor academic performance, among others such as dyslexia and left-right confusion (Mera, 2013). In summary, lateral crossings, ambidextrous, contradictory laterality and undefined laterality are characteristic factors of slow children when doing school activities, negatively affecting the quality of learning. Thus, children with these types of laterality tend to present problems of spatial vision, in mathematics, in literacy, in the space-time location, specific language disorders, developmental disorders, among other behavioral and intellectual development difficulties.

The objective of this study is to analyze the relationship between laterality at an early age and the construction of pre-reading processes.

\section{Materials and Methods}

\section{Population and sample}

The population of this study was made up of 34 children attending the development center. Children's "Casita de Amor" of the city of Portoviejo. We worked with an intentional non-probabilistic sample of 10 children since these infants are those with deficiencies in areas such as language associated with the pre-reading stages, according to which the group that has no problems was ruled out, thus avoiding possible biases in this correlation. The following inclusion criteria were met: Pre-school students of both sexes that range in age from 1 to 3 years, speak Spanish, with difficulties in sensory areas, with difficulties in motor areas, with difficulties in affective areas of development, students of the CDI "Casita of Love" from Portoviejo. Also, exclusion criteria such as pathological history at birth, low weight or developmental problems, use of psychiatric medication, psychopathological disorders. The main variable investigated was the lateralization process measured through 2 standardized tests: KD test and laterality test: neuropsychological test. The other 
study variable was the pre-reading stages. The KD test (King-Devick test) is a visual evaluation, prepared by (AT King and S. Devik, 1976) the same one that is conceptualized in the Medical Dictionary (Dorland, 2011) and in the Medical Dictionary (Mosby) (Figure 1) as the instrument for the evaluation of saccadic movements, which consists of a series of number tables. These letters are progressive, making it more difficult to read fluently due to the constant separation between the numbers. Figure 1 shows the letters of the KD Test.

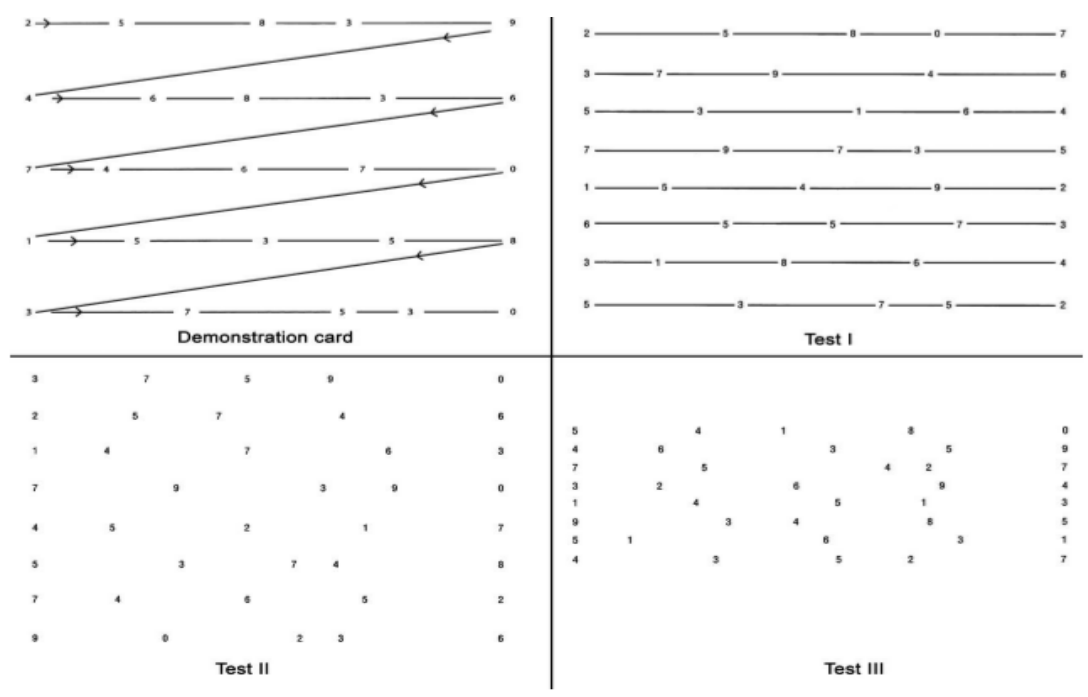

Figure 1. KD Test CardsKD

The test is composed of 4 parts, the demonstration letter, and 3 subtests. In the demonstration letter, the individual needs to read the numbers maintaining a conventional direction in the reading, which is helped by the arrows and their direction. To apply subtest 1 , the individual has to follow the same procedure, although now using specific eye movements. In subtest 2: The individual must follow the above procedure, however, in this exposure the marks of eye movement are not represented. For subtest 3: The individual has to continue the same procedure, but now the numbers are organized with greater spatial separation and with hardly any visual references. According to the presentation of the sheets, the mistakes made and the seconds it takes to read the letters are counted. Figure 2 shows the reading test used to assess the follow-up of the eyes.

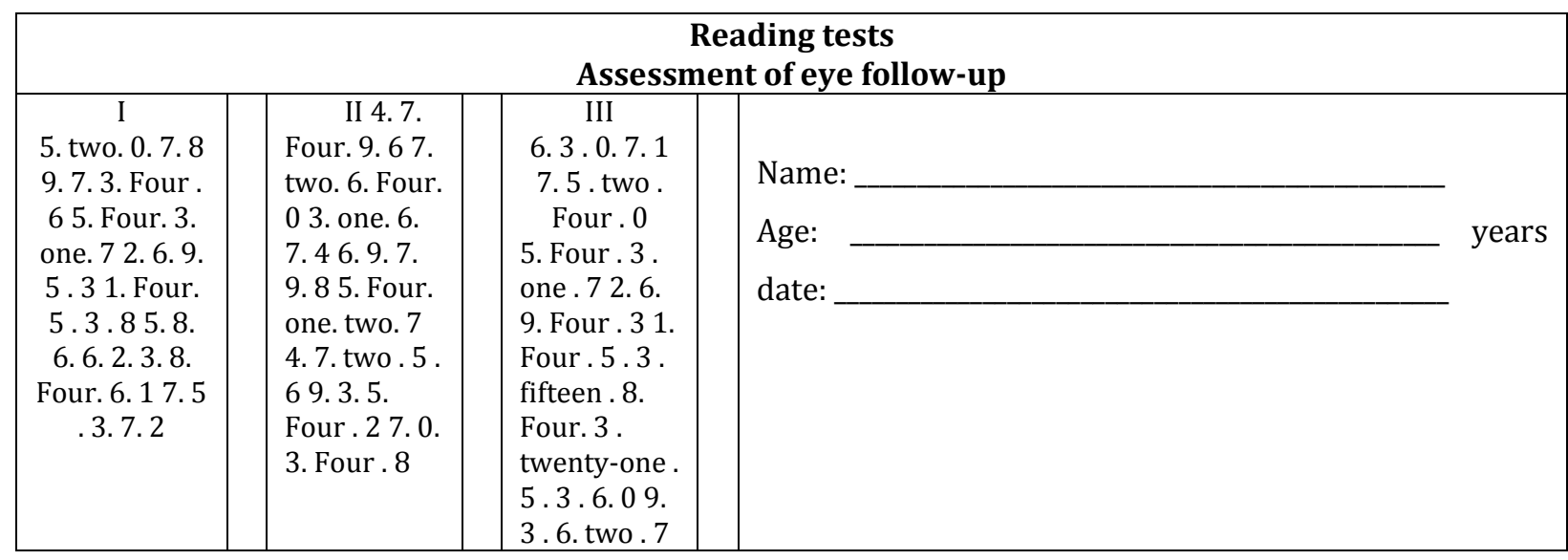

\begin{tabular}{|c|c|c|c|c|c|}
\hline & \multirow{2}{*}{ AGE } & \multicolumn{3}{|c|}{$\begin{array}{l}\text { TIME (according to } \\
\text { age) }\end{array}$} & \multirow{2}{*}{ TOTAL } \\
\hline & & I & II & III & \\
\hline Time & 6 & $\begin{array}{c}30.9 \\
8\end{array}$ & $\begin{array}{c}37.0 \\
5\end{array}$ & 51 & 119.03 \\
\hline
\end{tabular}

ERRORS (according to age)

\begin{tabular}{cccc}
\hline I & II & III & TOTAL \\
\hline \multirow{2}{*}{1.32} & $\begin{array}{c}3.8 \\
1\end{array}$ & $\begin{array}{c}10.8 \\
1\end{array}$ & 16.97
\end{tabular}

Cedeño, L. M. C., Zambrano, T. Y. M., Rengifo, J. C. Z., \& Loor, K. M. M. (2019). Laterality and pre-reading processes at an early age. International Journal of Health Sciences, 3(3), 44-54. https://doi.org/10.29332/ijhs.v3n3.369 


\begin{tabular}{|c|c|c|c|c|c|}
\hline Error margin & 6 & 10.1 & $\begin{array}{c}12.9 \\
6\end{array}$ & $\begin{array}{c}19.3 \\
9\end{array}$ & 40.92 \\
\hline Time & 7 & $\begin{array}{c}26.7 \\
1\end{array}$ & $\begin{array}{c}31.1 \\
2\end{array}$ & $\begin{array}{c}43.0 \\
6\end{array}$ & 100.89 \\
\hline Error margin & 7 & 5.97 & 8.75 & $\begin{array}{c}15.3 \\
6\end{array}$ & 25.16 \\
\hline Time & 8 & $\begin{array}{c}22.9 \\
8\end{array}$ & $\begin{array}{c}24.8 \\
9\end{array}$ & $\begin{array}{c}31.2 \\
6\end{array}$ & 79.13 \\
\hline Error margin & 8 & 6.37 & 7.75 & $\begin{array}{c}11.5 \\
9\end{array}$ & 27.35 \\
\hline Time & 9 & $\begin{array}{c}21.0 \\
2\end{array}$ & $\begin{array}{c}22.8 \\
9\end{array}$ & $\begin{array}{c}29.5 \\
3\end{array}$ & 73.44 \\
\hline Error margin & 9 & 7.2 & 7.5 & $\begin{array}{c}10.8 \\
2\end{array}$ & 26.03 \\
\hline Time & 10 & $\begin{array}{c}19.7 \\
2\end{array}$ & $\begin{array}{c}20.7 \\
9\end{array}$ & 27 & 68.27 \\
\hline Margin of error & 10 & 6.08 & 7.37 & $\begin{array}{c}10.2 \\
1\end{array}$ & 26.22 \\
\hline Time & 11 & $\begin{array}{c}17.5 \\
8\end{array}$ & $\begin{array}{c}18.9 \\
5\end{array}$ & $\begin{array}{c}20.3 \\
9\end{array}$ & 56.92 \\
\hline Margin of error & 11 & 4.6 & 4.51 & 7.45 & 13.85 \\
\hline Time & 12 & $\begin{array}{c}16.9 \\
4\end{array}$ & $\begin{array}{c}17.6 \\
8\end{array}$ & $\begin{array}{c}19.4 \\
2\end{array}$ & 54.04 \\
\hline Error margin & 12 & 3.6 & 4.43 & 5.31 & 13.51 \\
\hline Time & 13 & $\begin{array}{c}16.2 \\
9\end{array}$ & $\begin{array}{c}16.9 \\
6\end{array}$ & $\begin{array}{c}18.9 \\
8\end{array}$ & 52.23 \\
\hline Error margin & 13 & 2.52 & 2.72 & 3.26 & 7.5 \\
\hline Time & 14 & $\begin{array}{c}14.8 \\
6\end{array}$ & $\begin{array}{c}16.8 \\
7\end{array}$ & $\begin{array}{c}18.7 \\
3\end{array}$ & 50.46 \\
\hline Error margin & 14 & 2.4 & 2.33 & 2.49 & 5.84 \\
\hline
\end{tabular}

\begin{tabular}{cccc}
\hline 1.12 & 2.1 & 8.75 & 11.97 \\
\hline 0.34 & $\begin{array}{c}0.5 \\
3\end{array}$ & 2.48 & 3.35 \\
\hline 0.28 & $\begin{array}{c}0.4 \\
3\end{array}$ & 1.12 & 1.83 \\
\hline 0.25 & $\begin{array}{c}0.3 \\
3\end{array}$ & 0.62 & 1.2 \\
\hline 0.18 & $\begin{array}{c}0.2 \\
1\end{array}$ & 0.44 & 0.83 \\
\hline 0.12 & $\begin{array}{c}0.1 \\
2\end{array}$ & 0.36 & 0.59 \\
\hline 0.07 & $\begin{array}{c}0.0 \\
7\end{array}$ & 0.33 & 0.47 \\
\hline
\end{tabular}

Figure 2. Reading test. Assessment of eye follow-ups

To achieve the quality of saccadic movements, the time that confirms each error issued is added as a variable, so if there is a sum that falls below the general one in relation to age and the error frame, visualize a positive academic performance.

\section{Lateral test of the neuropsychological}

This test is an adaptation performed by (Martín et al., 2015), which includes 40 actions that the subject must perform using one side of the body. Table 1 shows these actions of the laterality test.

Table 1

Actions to be carried out in the Neuropsychological test laterality test

\begin{tabular}{|c|c|c|c|}
\hline Vision & Audition & Hand & Foot \\
\hline $\begin{array}{l}\text { Look through a } \\
\text { spyglass }\end{array}$ & $\begin{array}{l}\text { Listen to the sound of } \\
\text { the clock }\end{array}$ & Write & Hit a ball \\
\hline $\begin{array}{l}\text { Look through a small } \\
\text { tube }\end{array}$ & Listen to the wall & Light a match & Kick the air \\
\hline $\begin{array}{l}\text { The aim with your } \\
\text { finger }\end{array}$ & $\begin{array}{l}\text { Listen to noises on the } \\
\text { floor }\end{array}$ & Distribute cards & Cross your leg \\
\hline $\begin{array}{l}\text { Look closely through } \\
\text { the hole in a paper }\end{array}$ & $\begin{array}{l}\text { Bring an ear to the door } \\
\text { to listen }\end{array}$ & Clean shoes & $\begin{array}{l}\text { Write the name with your } \\
\text { foot on the floor }\end{array}$ \\
\hline $\begin{array}{l}\text { Look far away through } \\
\text { the hole in a paper }\end{array}$ & Talking on the phone & Opening and closing boats & Walking with one foot \\
\hline $\begin{array}{l}\text { Covering one eye to } \\
\text { look closely }\end{array}$ & Re-answering someone & $\begin{array}{l}\text { Pass small objects from } \\
\text { one container to another }\end{array}$ & Run with one foot. \\
\hline
\end{tabular}




\begin{tabular}{|c|c|c|c|}
\hline $\begin{array}{l}\text { Cover one eye to see } \\
\text { from afarfullest }\end{array}$ & $\begin{array}{l}\text { Differentiate thein two } \\
\text { boxes }\end{array}$ & Dot a paper & Walk with your foot \\
\hline $\begin{array}{l}\text { Approach from afar. } \\
\text { Bring a paper to one of } \\
\text { the eyes. }\end{array}$ & $\begin{array}{l}\text { Listen to a story by one } \\
\text { ear and cover the other. }\end{array}$ & Dot a paper & Walk with one foot \\
\hline $\begin{array}{l}\text { Imitate the shot with a } \\
\text { shotgun. }\end{array}$ & $\begin{array}{l}\text { Move an object and try } \\
\text { to guess what it is. }\end{array}$ & $\begin{array}{l}\text { Handle a puppet or } \\
\text { puppet. }\end{array}$ & $\begin{array}{l}\text { Try to pick up an object } \\
\text { with one foot. }\end{array}$ \\
\hline $\begin{array}{l}\text { Look through a large } \\
\text { tube. }\end{array}$ & $\begin{array}{l}\text { Listen to the external } \\
\text { sound through the } \\
\text { window pane. }\end{array}$ & Take a spoon. & Climb a step of a ladder. \\
\hline
\end{tabular}

When these actions are carried out, the hemisphere with which they were executed must be registered. When obtaining the actions and records of their lateral dominance, an interpretation of data can be executed that allows defining the type of laterality. Table 2 shows the content of the interpretation tests.

Table 2

Test results and interpretation

\begin{tabular}{ll}
\hline Content of the tests & Interpretation \\
\hline $\begin{array}{l}\text { Vision, hearing, right hand, and foot } \\
\text { Vision, hearing, left hand and left foot } \\
\text { Vision, hearing, right hand and left foot }\end{array}$ & $\begin{array}{l}\text { Right } \\
\text { Left, } \\
\text { Right in the process of lateralization of the foot (in many } \\
\text { cases it is lateralized later). May have foot crossing. }\end{array}$ \\
$\begin{array}{l}\text { Left vision, hearing, right hand, and foot left } \\
\text { hearing, }\end{array}$ & $\begin{array}{l}\text { Right hand with left visual crossover } \\
\text { Vision, hand and right foot }\end{array}$ \\
$\begin{array}{l}\text { Vision and hearing the left hand and foot. } \\
\text { Vision, hearing and right foot, left hand. }\end{array}$ & $\begin{array}{l}\text { Right hand with left hearing crossover Right } \\
\text { It is not usually given. The hand is very important and it is } \\
\text { better to perform more specialized tests. }\end{array}$ \\
\hline
\end{tabular}

\section{Method}

As part of the procedure, the topic was discussed and a meeting was held with the director of the children's center and the educators, to allow the approval and management of the research process. Through this, the 10 children who were part of the group evaluated were selected. Once the above was established, the relevant instrument was prepared, such as the KD tests and the Laterality test: a neuropsychological test and a specific area were selected for the place where the tests were performed individually. To perform the data analysis, we proceeded to the statistical analysis, both correlational and descriptive, a collection of information was carried out that was transferred to different documents evaluated by Excel Analyze 3.0, in order to obtain, frequency, percentages, and values Statisticians Regarding the descriptive analysis, it is sought to give character to the research sample in relation to its variables. On the other hand, the information presented by frequencies and percentages in the following: Absolute frequencies: in which the number of subjects in each area are counted, relative frequencies (percentages): they count the number of subjects in each area, but that is divided by the total, valid percentage: this is manifested by presenting missing values (subjects that do not have that data) and thus is responsible for eliminating them from the total to calculate the percentage, and accumulated percentage: sum the percentages of each category according to the variable.

In another area, the Chi-square test is one of those applied in the case of analyzing the relationship between variables; then placing the data in different tables. In the first, contingency information is presented, which reflects the number of individuals per category in relation to the variables analyzed. The second reveals the significance that this relationship has, in that aspect different coefficients are evident, which must be interpreted as follows: when it is less than 0.05 the relationship is significant, while the higher the value, the greater the intensity of the relationship.

Cedeño, L. M. C., Zambrano, T. Y. M., Rengifo, J. C. Z., \& Loor, K. M. M. (2019). Laterality and pre-reading processes at an early age. International Journal of Health Sciences, 3(3), 44-54. https://doi.org/10.29332/ijhs.v3n3.369 


\section{Results and Discussions}

According to Table 3, the diestrixmo constitutes the type of common laterality in the present case.

Table 3

Frequency of laterality

\begin{tabular}{clllll}
\hline & & Frequency & & Percent valid & Percent Cumulative \\
\hline \multirow{6}{*}{ Valid } & Right & 17 & 50.00 & 50.00 & 50.00 \\
& Zurdo & 8 & 23.53 & 23.53 & 73.53 \\
& Cross & 6 & 17.65 & 17.65 & 91.18 \\
& Undefined & 3 & 8.82 & 8.82 & 100.0 \\
& Total & 34 & 100.0 & 100.0 & \\
\hline
\end{tabular}

Table 4 shows the distribution of the sample according to the quality of the saccadic movements (adequate or inadequate). In this case, it is observed that the apparent fashion is presented in suitable or appropriate movements.

Therefore, the study on the correspondence between academic performance and variables (stages of prereading and laterality), data presented through contingency tables and chi-square tests are presented. By expressing the different contributions previously described in the theoretical framework, it can be specified that a poor definition of lateralization in children can have a significant impact and impact on the teachinglearning process; in this way it is relevant to analyze the presence of well-defined and poorly defined laterality according to the group (with adequate and inadequate movements). For the pre-reading level, based on the scores for each test in each case, an average score is calculated using the frequency table.

Table 4

Frequency saccadic movements

\begin{tabular}{lllll}
\hline & Frequency & Percentage & Valid & $\begin{array}{l}\text { Percentage } \\
\text { Accumulated } \\
\text { Percentage }\end{array}$ \\
\hline Adequate & 24 & 70.56 & 70.56 & 70.56 \\
Not suitable & 10 & 29.42 & 29.42 & 100 \\
Total & 34 & 100.0 & 100.0 & \\
\hline
\end{tabular}

According to Figure 3, the pre-reading level is associated with laterality based on the percentages of frequencies for each case valid on laterality. The total score is the sum of the identified readings per minute, the nonsense words and the correct words per minute.

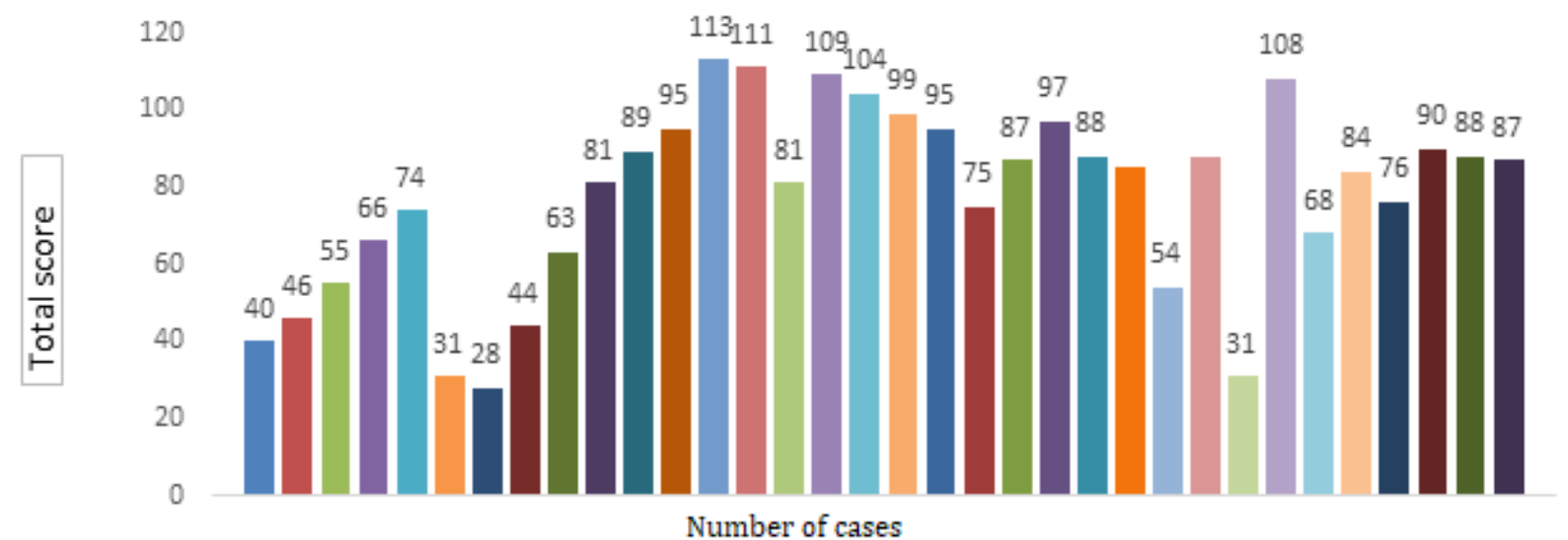

Figure 3. Pre-reading levels frequencies 
Using this data, a table is created and the hypothesis test is evaluated in the statistical software R. Pearson's method for chi-square was selected. The result of the hypothesis test yields a probability value of 0.00040348 , lower than the level of significance alpha $=0.05$ that uses the $\mathrm{R}$ test by default. It is concluded that the variables are not independent of each other, laterality and pre-reading level, they interact and therefore are related. Table 6 shows the percentage of laterality frequency.

Table 6

Frequency percentages

\begin{tabular}{llllll}
\hline & $\begin{array}{l}\text { Identified readings } \\
\text { per minute }\end{array}$ & \multirow{2}{*}{ Nonsense } & $\begin{array}{l}\text { Words Correct } \\
\text { words per minute }\end{array}$ & $\begin{array}{l}\text { Comprehension } \\
\text { score }\end{array}$ & $\begin{array}{l}\text { Total } \\
\text { Note }\end{array}$ \\
\hline Right & 19.04 & 3.17 & 5.77 & 0.28 & 28.26 \\
Left handed & 3.81 & 0.63 & 1.15 & 0.06 & 5.65 \\
Crusade & 7,62 & 1.27 & 2.31 & 0.11 & 11.30 \\
Undefined & 7.62 & 1.27 & 2.31 & 0.11 & 11.30 \\
\hline
\end{tabular}

The objective of this study was to analyze the relationship between laterality at an early age and the construction of pre-reading processes. Which according to the obvious results show that not only is there a relationship between both variables, but also the aforementioned hypothesis was positive and significant, in this, it was expected to find a positive relationship between laterality and pre-reading processes, which means that while there is a disorder in the laterality of the subject. When analyzing the indicators of pre-reading levels, based on the results of laterality and pre-reading levels (See Table 6), the correlation can be verified. The previous result is related to several that coincide with this conclusion, one of them called $A$ world for rights, a theme of laterality, written by (Valenzuela, 2009), it shows that there is a greater incidence in the predominant literalities both of the extremities as of the manual oculus coordination, these are fundamental to be able to develop motor skills in the subjects of study, who in this case were of legal age. A case closer to the present study is the one that manifests (González \& Hornauer, 2014), in which the language processes suppose a superior function in the human being in which multiple cortices and specific areas of the brain for the motor part participate, tactile, visual and auditory. According to Fajardo (2008), to ensure the acquisition of reading-writing skills there must be correct identification of the predominant hemisphere.

With regard to the teaching-learning process of literacy, this is not only long but also complex since it lasts a lifetime. But according to the research developed by Cano (2015), it is important that it be developed from the stage of early childhood education in order to favor the subsequent learning of future knowledge. Individually, each student in the sample studied showed skills according to their chronological age, but 4 of them presented severe delays in their pre-reading processes, 4 evidenced a difficulty during the assessments taken, finally, 2 of them showed a difficulty, but they managed to complete the task before the expected moment. In another study (Mayolas et al., 2010), it considers that there is a close relationship between laterality and school learning, this thanks to a study conducted on a sample of 170 children in ages 6 and 7, where it was evaluated laterality, it was evidenced that the greater the knowledge of laterality and limb dominance, the greater the results of school learning. The research of Mozo (2017), focuses on only one of the students, it seeks to intervene both in speech alterations and in those of laterality, thus assessing the subject's diversity of abilities in order to intervene to their needs, favoring their capacities From this intervention, variables such as family, sensory stimulation, among other things, were introduced into the neuropsychological intervention program.

Regarding laterality, it is a nonexistent topic within the CIBV studied, despite its program that develops social, emotional and cognitive skills in early childhood; and at this age, parents and educators can see difficulties that limit acquiring pre-reading functions typical of preschool ages and determine school failure or success. Each case studied was different, in each one we observed different characteristics and spectra that allowed us to generate inferences about laterality and its pre-reading process, showing that a large part of the children, having a motor difficulty, are students with delays in their processes. Specific, writing and language. On the other hand, there is a laterality study in which they use the Harris test in children ages of $3 * 6$ years, in this it was possible to measure the psychomotor skills of the subjects in terms of superior, inferior, ocular, and

Cedeño, L. M. C., Zambrano, T. Y. M., Rengifo, J. C. Z., \& Loor, K. M. M. (2019). Laterality and pre-reading processes at an early age. International Journal of Health Sciences, 3(3), 44-54. https://doi.org/10.29332/ijhs.v3n3.369 
auditory laterality. The results when comparing ages were evident, but with regard to laterality there are clear difficulties in ocular, manual and superior work; corresponding to the results established in this investigation (Ferradas, 2015).

\section{Conclusion}

It is necessary to remember what he mentioned at the time (Claude, 1978) cited by (Ferradas, 2015), about laterality disorders, this author said that those disorders have a negative influence on school learning, including motor skills; Given this, it is not only necessary to take matters on the subject, but also to detect and intervene in future cases, so that future repercussions can be prevented.

\section{Acknowledgments}

To María Rodríguez Gámez, Ph.D. and to Ab. Antonio Vázquez Pérez, Mgs. For his successful comments and valuable contributions to this research. 
References

Anthony, K. A., Oshoke, S., \& Slyvester, O. (2017). Assessment of entrepreneurial education and diversity management: a gateway to sustainable development in Nigeria. International Research Journal of Management, IT and Social Sciences, 4(1), 53-60.

Cano B. (2015). Literacy in early childhood education: to improve their development activities in the classroom. Final degree project. University of Valladolid.

Claude, P. (1978). Morphological factors influencing transepithelial permeability: A model for the resistance of theZonula Occludens. The Journal of membrane biology, 39(2-3), 219-232. https://doi.org/10.1007/BF01870332

Conde, L. (2004). A história do sapato no século 20. Alexa Cultural.

Fajardo L. (2008). Approach to the relationship between brain and language. Hispanic Linguistics Notebook. (eleven). P 93.104. Pedagogical and Technological University of Colombia.

Ferradas C. (2015). Evaluation of laterality through the Harris test in children aged 3 and 6 years. Final degree project. University of Valladolid.

Gómez-Martín, A., Hernández, A. F., Martínez-González, L. J., González-Alzaga, B., Rodríguez-Barranco, M., López-Flores, I., ... \& Lacasana, M. (2015). Polymorphisms of pesticide-metabolizing genes in children living in intensive farming communities. Chemosphere, 139, 534-540.

González D. (2016). Relationship between laterality and the development of the literacy process. End of Material Work International University of La Rioja.

González R., \& Hornaeur, A. (2014). Brain and language, Magazine Hospital Clínico Universidad de Chile HCUCH, 143-153.

Lenneberg, E. (1967). Biological foundations of language. New York: Willey

Mayolas, M.C., Villarroya, A., \& Reverter, J. (2010). Relationship between laterality and school learning. Notes Physical Education and Sports, 101, 32-42.

Mera, G. (2013). Laterality, perceptual processes and academic performance. Master's thesis International University of La Rioja.

Moneo, A. (2014). The laterality and its influence on school learning. University of La Rioja.

Mozo, L. (2017). Proposal for intervention in a child with laterality and dyslalia problems. Final Degree Project. University of Valladolid

Pérez, A. V., Gámez, M. R., Briones, V. F. V., Viteri, C. G. V., \& Molina, L. A. V. (2018). Sustainable development seen from environmental training in university linkage. International Journal of Life Sciences, 2(1), 12-20. https://doi.org/10.29332/ijls.v2n1.75

Pérez, M. (1999). The professionalization of the teacher: improvement, research in the classroom, analysis of the practice. 21st century of Spain Editors.

Portellano, J.A. (2012). Introduction to neuropsychology. Madrid: McGraw-Hill.

Sánchez, M. L., Vecino, E., \& Coveñas, R. (2013). Distribution of methionine-enkephalin in the minipig brainstem. Journal of chemical neuroanatomy, 50, 1-10. https://doi.org/10.1016/j.jchemneu.2013.03.002

Sassano, A. (1989). On the facial structure of the set covering polytope. Mathematical Programming, 44(1-3), 181-202. https://doi.org/10.1007/BF01587087

Spionek, H. (1985). Orientation disorders in the right and left side of the body diagram in ontogenesis. Warsaw. PWN.

Valenzuela, H. (2009). A theme of laterality. End of postgraduate work. National Pedagogical University Francisco Morazan.

Cedeño, L. M. C., Zambrano, T. Y. M., Rengifo, J. C. Z., \& Loor, K. M. M. (2019). Laterality and pre-reading processes at an early age. International Journal of Health Sciences, 3(3), 44-54. https://doi.org/10.29332/ijhs.v3n3.369 


\section{Biography of Authors}

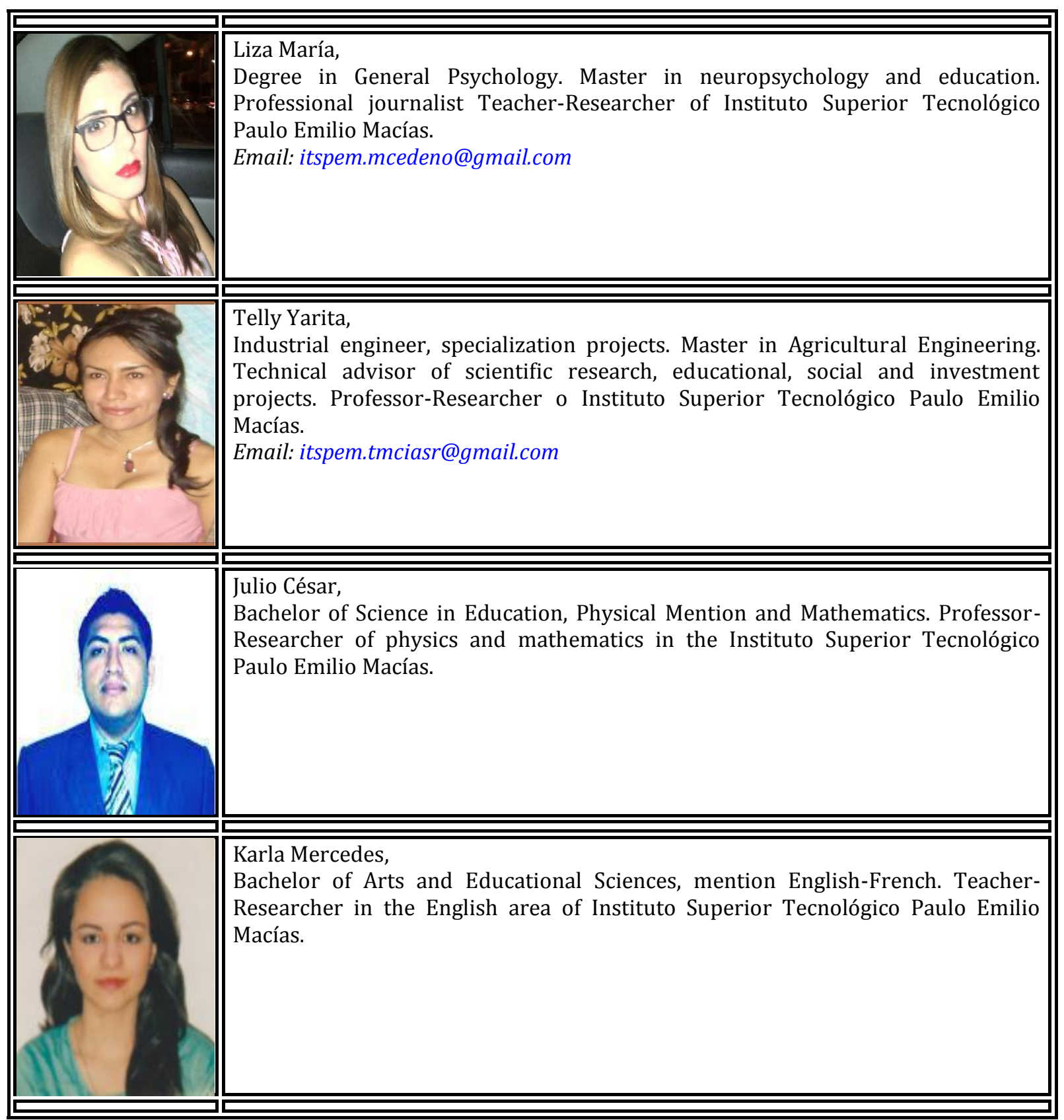

